\title{
Investigation on modal transient response analysis of engine crankshaft structure
}

\author{
M. S. M. Sani, M. M. Noor, M. S. M. Zainury, M. R. M. Rejab, \\ K. Kadirgama \& M. M. Rahman \\ Universiti Malaysia Pahang, Malaysia
}

\begin{abstract}
The crankshaft is a very crucial part in an internal combustion engine. This paper presents the findings of the mode shape and natural frequency of 3 cylinder 4 stroke engine crankshafts. Both experimental and computational methods were carried out to determine the modal parameter or dynamic characteristics, which are natural frequency, damping factor and mode shape. The prediction of the dynamic properties of the chassis is of great significance in determining the natural frequencies of the structure. The experiment is done by using an impact hammer to excite the crankshaft and data is recorded using a data acquisition system (DAS) connected to a sensor located on the crankshaft. Computational modal analysis on the crankshaft structure is simulated using finite element software. It can be seen from the results that there is a good agreement between the experimental and computational results in terms of modal parameter with a small discrepancy. The modal analysis techniques are essential for automotive crankshaft structure design.
\end{abstract}

Keywords: natural frequency, mode shape, modal analysis, crankshaft, finite element.

\section{Introduction}

In the Otto cycle engine or Internal Combustion Engine (ICE), a piston, or series of them, will reciprocate in a linear manner. Crankshaft linear motion needs to be translated into rotational motion in order for the power to be generated from the movement of the piston. Natural frequency is the frequency at which a system naturally vibrates once it has been set into motion. In other words, the natural 
frequency is the number of times a system will oscillate (move back and forth) between its original position and its displaced position, if there is no outside interference. If the operation frequency of a crankshaft is near to or the same as its natural frequency, resonance will happen and the effect on the crankshaft or even the ICE itself is catastrophic.

Torsional vibrations of reciprocating engines arise due to the application of periodic combustion forces in the cylinder and the associated inertial forces of rotating and articulating members, such as the crankshaft, the camshaft, and the connecting rod [1]. In many cases the most dangerous vibrations are those linked with modes that are essentially torsional vibration of crankshafts [2]. Every power stroke the transmitted piston force is initially increased in magnitude and is subsequently reduced at the end of the stroke. This action results in an imparted twist-untwist action of the crankshaft, causing torsional vibrations to occur [1].

Draminsky [3], Hestermann and Stone [4] observed that some systems exhibit high vibration amplitudes at unexpected rotational speeds. The cause of unexpected multiples of engine speed is the variable inertial effects due to large displacement dynamics of rotating and articulating members or uneven cylinder firing. Crankshaft noise, vibration and harshness (NVH) characteristics was developed for simulation purpose by Katano et al. [5]. Their method focused on the resonance of the crankshaft, the flexibility and the oil film characteristics of the main bearings. Hestermann and Stone [6] was developed a number of models to compute the effect of variable inertia on a single cylinder engine in both time and frequency domains. Their research effort showed that the reciprocating engines have the potential to exhibit secondary critical speeds due to the frequency inter modulation between the engine speed, the natural frequency orders, and the forcing frequency orders. Song et al. [7] was analyzed the coupled crankshaft vibration and this coupling effect generates high amplitudes of vibrations when the natural frequencies of the torsional and the axial vibrations are equal to one another or when the axial vibration frequency is double that of the torsional mode. The crankshaft flexibility has significant influence on the system dynamical behaviour [8]. Pasricha and Carnegie [9] was developed the model with changing inertia of a multi-cylinder engine. Their model did not involve driving forces and loads. Considering the effect of the changing inertia and prescribed time-dependent forcing functions in a crankshaft torsional vibration analysis by Brusa et al. [2]. More advanced models can be found in $[10,11]$, which involve the changing inertia and external forces as functions of crankshaft motion. However, the crankshaft is treated as a rotational spring in their models. The crankshaft deformation is described using finite elements and modal coordinates in another model [12]. The modal vectors obtained by ignoring the changing inertia of the engine block are used to approximate the true rotation-dependent modal vectors.

Hence, this paper focused on experimental modal analysis (EMA) and finite element analysis (FEA) to determine modal parameter such as natural frequency, damping factor and mode shape. 


\section{Experimental Modal Analysis (EMA)}

Experimental study of structural vibration has made significant contributions for better understanding in vibration phenomenon [13]. Normally, experimental observations are always to determine the nature of vibration response level and to verify theoretical models and predictions [14]. EMA is widely used in many engineering applications especially analysis involving vibration mechanism. Model parameters such as natural frequency, mode shape and damping ratio were extracted from the structure experimentally. This experiment has done to determine dynamics characteristics of car chassis structure by impact hammer and shaker method [15]. Researcher compares natural frequency value between impact and shaker method.

In order to performed analysis on crankshaft structure, CAD design from solidworks was converted to ME' Scope software. Then, the structure is hanged on the test rig using bungee cord as shown in Figure 1. Crankshaft structure was divided into 16 grid points where at this point, Frequency response functions were measured in the range of $0-1500 \mathrm{~Hz}$ to identify modal parameters. These 16 points were chosen to give adequate spatial resolution to describe the global structural mode shapes.

Impact hammer test was implemented in the experimental modal test, which was used to excite the 16 degree of freedom (DOF) on the crankshaft structure. The force transducer was connected to the hammer at the bottom of the handle. Figure 2 shows the accelerometer or sensor was fixed at one reference DOF and the hammer was roving through all the 16 DOF. Data analyzer was used to convert the signal response which was in time domain to the frequency domain.

For impact hammer excitation, each accelerometer response DOF is usually fixed and reflects a reference DOF. The hammer is then moved around the structure and used to excite every 16 DOF needed in the model. The relationship between input (force excitation) and output (vibration response) of a linear system is given by:

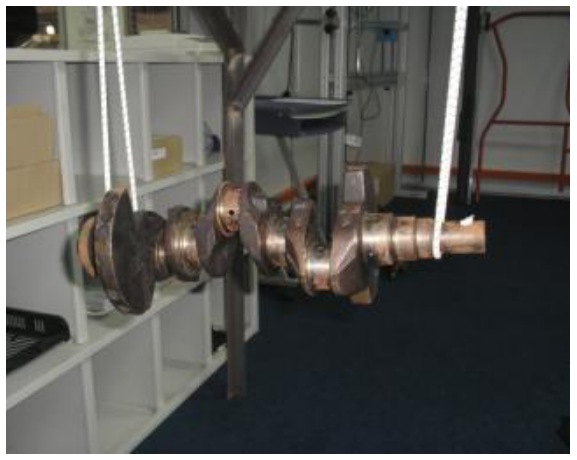

Figure 1: Crankshaft supported on the test rig using bungee cord.

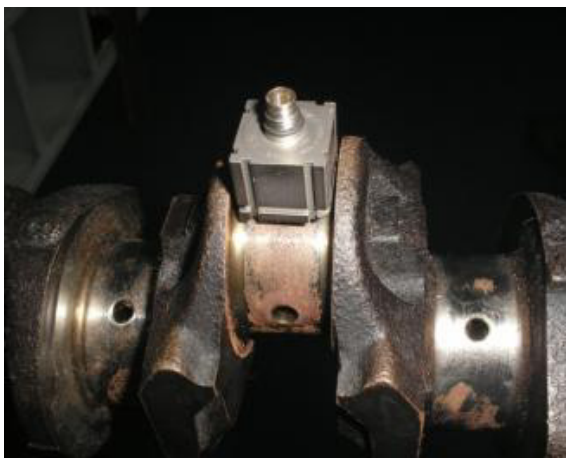

Figure 2: Tri-Axial Accelerometer test mounted on the crankshaft. 


$$
Y_{i}=\sum_{j} H_{i j} X_{j}
$$

where $Y_{i}$ is the output spectrum at DOF $i, X_{j}$ is the input spectrum at DOF $j$, and $H_{i j}$ is the frequency response function (FRF) between DOF $j$ and DOF $i$. The output is the sum of the individual output caused by each of the inputs. The FRF's are estimated from the measured auto and cross-spectra of and between input and output. Only one response DOF is needed by one accelerometer position (point and direction) in impact hammer test. Equation related to the single-input, single-output test configuration as follow:

$$
\left\{\begin{array}{c}
Y_{1} \\
Y_{2} \\
Y_{3} \\
\vdots \\
Y_{n}
\end{array}\right\}=\left[\begin{array}{ccccc}
H_{11} & H_{12} & H_{13} & \cdots & H_{1 n} \\
H_{21} & H_{22} & H_{23} & \cdots & H_{2 n} \\
H_{31} & H_{32} & H_{33} & \cdots & H_{3 n} \\
\vdots & \vdots & \vdots & \cdots & \vdots \\
H_{n 1} & H_{n 2} & H_{n 3} & \cdots & H_{n n}
\end{array}\right]\left\{\begin{array}{c}
X_{1} \\
X_{2} \\
X_{3} \\
\vdots \\
X_{n}
\end{array}\right\}
$$

\section{Finite Element Analysis (FEA)}

Finite element analysis (FEA) is a computer simulation technique used in engineering analysis. It uses a numerical technique called the finite element method (FEM). Development of the finite element method in structural mechanics is usually based on an energy principle such as the virtual work principle or the minimum total potential energy principle. Computations of natural frequencies, mode shapes, critical speeds, steady state responses, and transient responses play important roles in the design, identification, diagnosis and control of rotor-bearing systems [16]. A spatial finite line element method in an analysis of rotors, including crankshafts was utilized by Bagci and Rajavenkateswaran [17]. Smaili and Khetawat [18] were proposed a spatial fournode beam element based on Timoshenko's theory for the modelling of crankshafts. This study models practical crankshafts by using both a tetrahedron element and a beam element and compares the analytical results with data from modal testing. Stephenson et al. [19] showed an excellent agreement between the measured frequencies and the frequencies calculated by using an axisymmetric solid finite element model. Furthermore, Stephenson and Rouch [20] presented axisymmetric solid finite elements with matrix reduction in modelling a rotating shaft.

Figure 3 shows the complete computer aided design for crankshaft structure which is developed utilizing the solidworks software. The finite element model was developed using the tetrahedron element meshing technique.

In prediction of analytical dynamic characteristics of crankshaft structure, the normal modes analysis was performed using commercial FEM Software, Algor. The free-free boundary condition was adopted in order to simulate the structure 


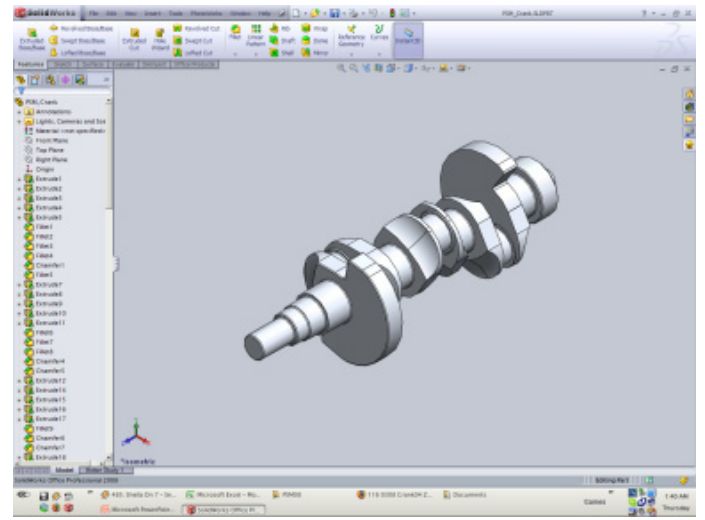

Figure 3: Crankshaft modelled in solidworks.

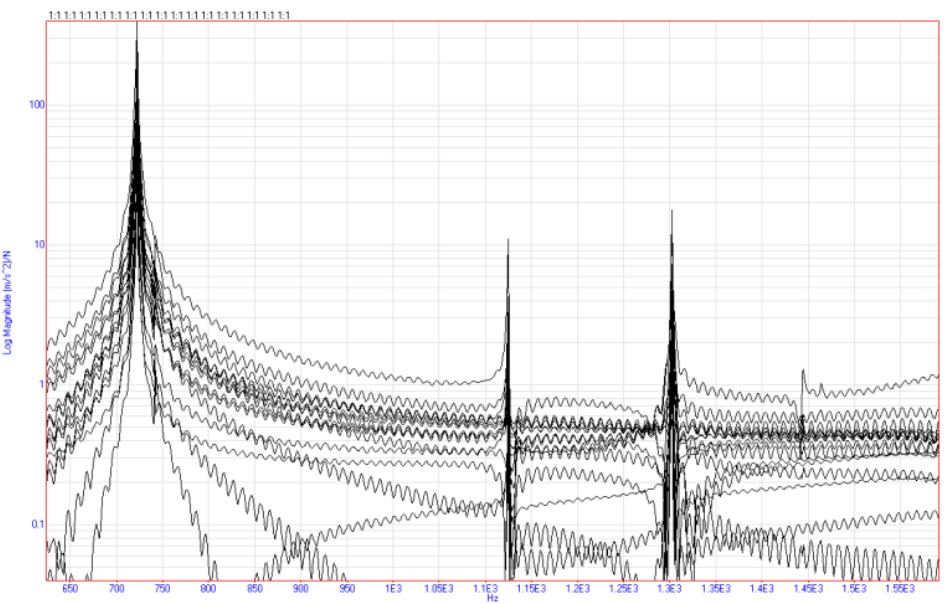

Figure 4: $\quad$ Superimposed FRF on the X-axis.

natural frequencies and mode shape vectors. Neither constraints nor loads were assigned to stimulate this free-free boundary condition. This analysis was perform on modal linear analysis with material as a iron, gray cast ASTM A-48 grade 60 , tetrahedral element type, lower cut-off frequency as $40 \mathrm{~Hz}$ and upper cut-off frequency as $1500 \mathrm{~Hz}$. The reason for setting frequency at $40 \mathrm{~Hz}$ is to avoid the solver from calculating rigid body motions which have the frequency at $0 \mathrm{~Hz}$.

\section{Results and discussion}

Figures 4, 5 and 6 show the superimposed FRF at 16 points for impact hammer test on the $\mathrm{X}, \mathrm{Y}$ and $\mathrm{Z}$ axes. Impact hammer test shows better FRF results because of mass loading are negligible. 


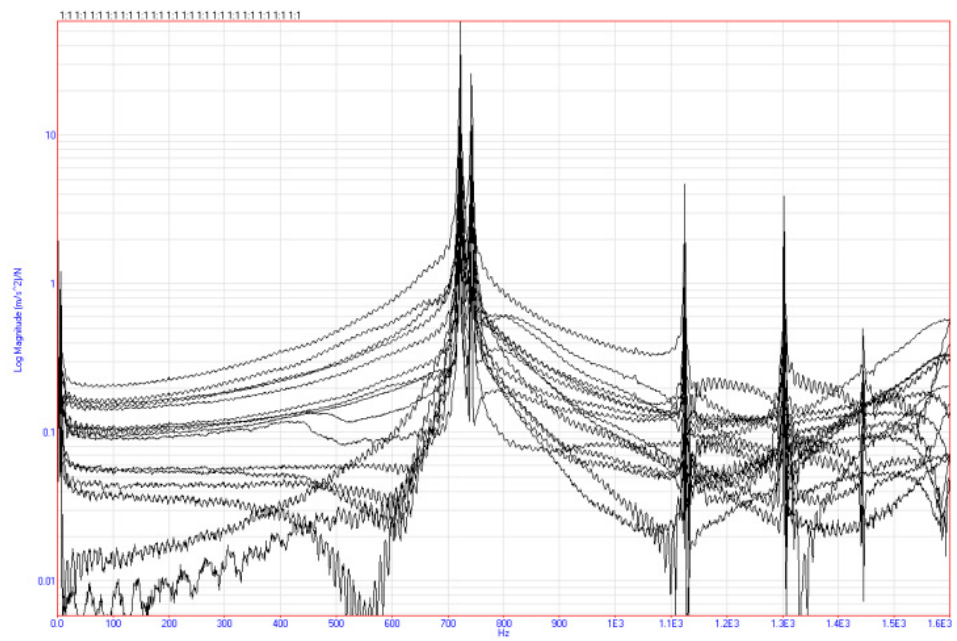

Figure 5: Superimposed FRF on the Y-axis.

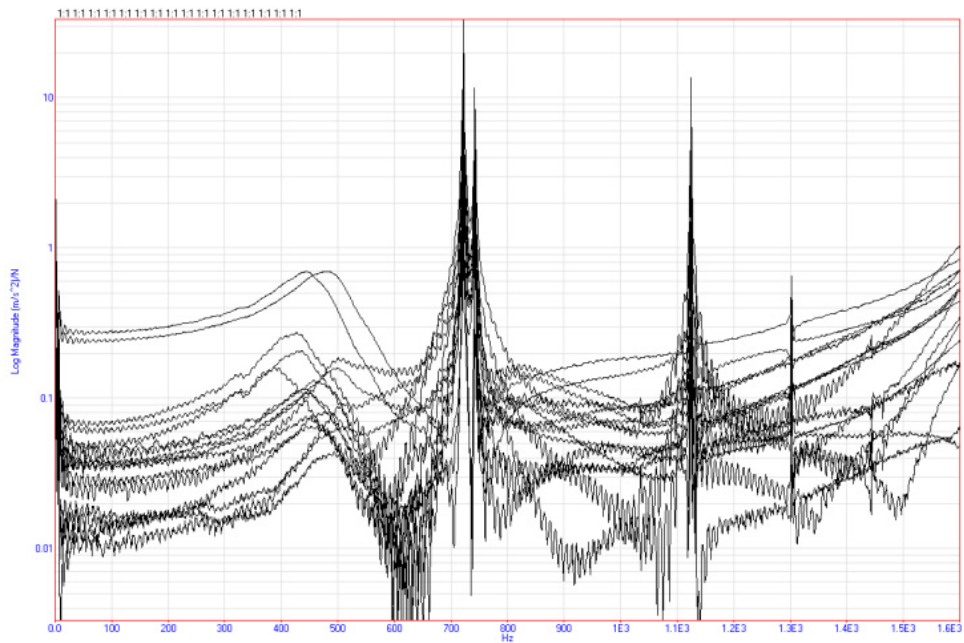

Figure 6: $\quad$ Superimposed FRF on the Z-axis.

Table 1 is listed the natural frequency of different modes of the crankshaft structure extracted from experimental modal analysis with roving impact hammer test. It can be seen from Table 1 that the value of natural frequency results from $\mathrm{X}, \mathrm{Y}$ and $\mathrm{Z}$ axis are closely related with each other. The discrepancy percentage is less than $10 \%$ which means these results are valid.

Table 2 shows that summary of natural frequencies value based on mode and percentage of meshing. From the literature selection of FEA natural frequency is referred to convergence value of meshing ratio. Obviously shows that the natural frequencies every mode start converge after $60 \%$ meshing ratio. 
Table 1: $\quad$ Experimental natural frequency on the $\mathrm{X}, \mathrm{Y}$ and $\mathrm{Z}$ axes.

\begin{tabular}{cccc}
\hline \multirow{2}{*}{ Mode } & \multicolumn{3}{c}{ Natural Frequency, Hz } \\
\cline { 2 - 4 } & $\mathbf{X}$ & \multicolumn{1}{c}{ Y } & $\mathbf{Z}$ \\
& axis & axis & axis \\
\hline 1 & 668 & 724 & 675 \\
2 & 722 & 742 & 724 \\
3 & 1030 & 995 & 1075 \\
4 & 1248 & 1230 & 1210 \\
5 & 1580 & 1510 & 1545 \\
\hline
\end{tabular}

Table 2: $\quad$ Summary of FEA natural frequency.

\begin{tabular}{|c|c|c|c|c|}
\hline \multirow[t]{2}{*}{ Mode } & \multicolumn{4}{|c|}{ Natural Frequency, $\mathbf{H z}$} \\
\hline & $\begin{array}{c}100 \% \\
\text { mesh }\end{array}$ & $\begin{array}{l}80 \% \\
\text { mesh } \\
\end{array}$ & $\begin{array}{l}60 \% \\
\text { mesh } \\
\end{array}$ & $\begin{array}{l}40 \% \\
\text { mesh }\end{array}$ \\
\hline 1 & 708.682 & 688.494 & 670.5 & 653.56 \\
\hline 2 & 727.661 & 707.619 & 689.55 & 672.08 \\
\hline 3 & 1098.9 & 1069.48 & 1042.2 & 1015.8 \\
\hline 4 & 1273.63 & 1248.92 & 1228.8 & 1210 \\
\hline 5 & 1664.23 & 1625.1 & 1583.9 & 1534.9 \\
\hline
\end{tabular}

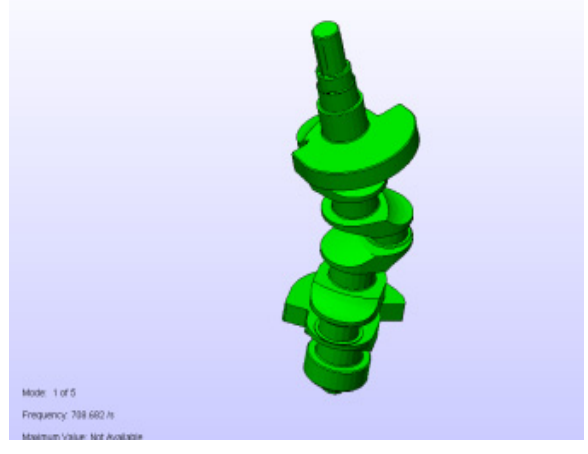

Figure 7: $\quad 1^{\text {st }}$ mode, bending.

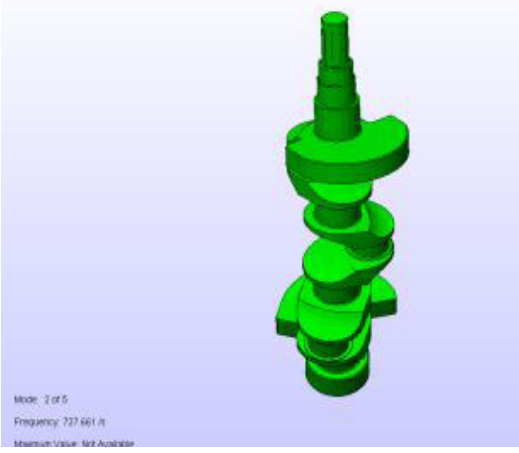

Figure 8: $\quad 2^{\text {nd }}$ mode, bending.

Figures 7 to 11 show the deflection types for all modes from 1 to 5 . The deflection types for all mesh sizes is the same with bending in mode 1, 2, 3 and 5 while torsion in mode 4.

Correlation is processes to evaluate how close the frequency FEA model with the experimental model. Discrepancies will always exist between the FEA model and EMA model. This may attributed to the possibilities error in experimental 


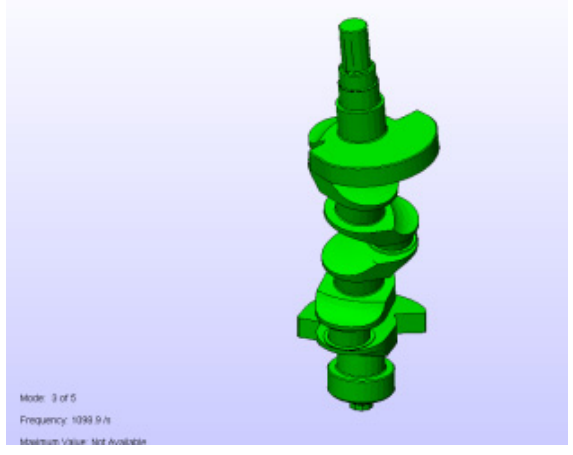

Figure 9: $\quad 3^{\text {rd }}$ mode, bending.

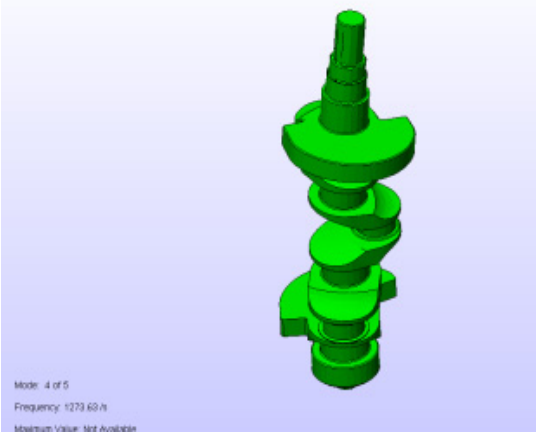

Figure 10: $\quad 4^{\text {th }}$ mode, torsion.

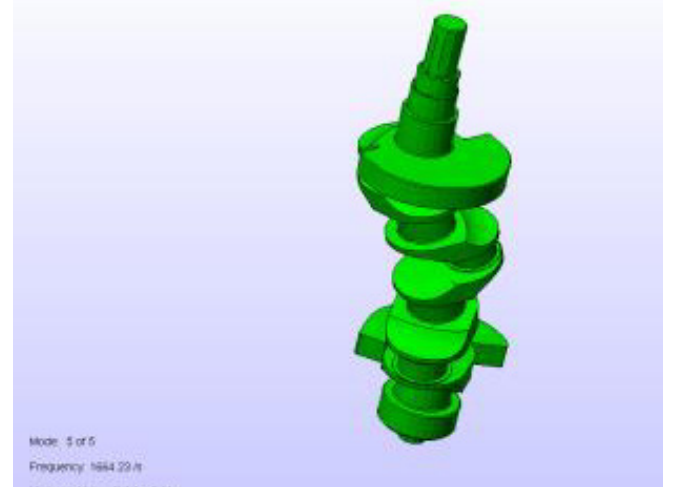

Figure 11: $\quad 5^{\text {th }}$ mode, bending.

Table 3: $\quad$ Mode pairs with frequency difference.

\begin{tabular}{ccccc}
\hline Mode & $\begin{array}{c}\text { EMA } \\
\text { Frequency } \\
(\mathrm{Hz})\end{array}$ & $\begin{array}{c}\text { FEA s } \\
\text { Frequency }(\mathrm{Hz})\end{array}$ & $\begin{array}{c}\text { Error } \\
(\%)\end{array}$ & $\begin{array}{c}\text { MAC } \\
(\%)\end{array}$ \\
\hline 1 & 668 & 670.5 & 0.37 & 92.4 \\
2 & 722 & 689.55 & 4.4 & 87.5 \\
3 & 1030 & 1042.2 & 1.17 & 93.5 \\
4 & 1248 & 1228.8 & 1.53 & 83.6 \\
5 & 1580 & 1583.9 & 0.24 & 91.2 \\
\hline
\end{tabular}

data such as the measurements could have been carried out at an imperfect set-up noise and existence of inherent model parameter errors and model structure errors. Modal Assurance Criteria matrix was performed and test would indicate how good the FE modes correlate with the test modes. The high MAC values $(>75 \%)$ would show which FE mode shapes resembles to which test modes. Table 3 shows the mode pairs with frequencies difference. Small discrepancy 
between EMA and FEA and MAC results indicate that the mode frequencies were similar shapes.

\section{Conclusions}

In conclusion, the dynamic characteristics of crankshaft structure could be determined using FEA analysis when the right element and method are used. However, due to model complexity, some simplification on design was done and large error could be expected. Therefore, for the model to be useful, EMA should be carried out to verify the real structure. For dynamic analysis, the FEA model proved to have positive or strong correlation with EMA in the frequency and mode shape. Through research on working frequency and natural frequency of the crankshaft is crucial to avoid resonance during operation.

\section{Acknowledgement}

The authors would like to express their deep gratitude to Universiti Malaysia Pahang (UMP) for providing the laboratory facilities and financial support.

\section{References}

[1] Boysal, A. and Rahnejat, H., Torsional Vibration analysis of a multi-body internal combustion single cylinder engine model, Journal of Applied Math. Modeling, vol 21:pp 481-493, August 1997

[2] Brusa, E., Delprete, C., and Genta, G., Torsional vibration of crankshafts: effects of non-constant moments of inertia, Journal of Sound and Vibration, 205(2), pp135-150, 1997

[3] Draminsky, P., Extended treatment of secondary resonance. Ship Build. Marine Eng., 88, pp180-186, 1998

[4] Hestermann, D. C. and Stone, B. J., The causes of torsional resonance in reciprocating engines and pumps at other than integer multiples of the fundamentals excitation frequency. IMechE International Conference on Vibration and Rotating Machinery, C432/041, pp. 517-521, 1992

[5] Katano, H. Iwamoto, A. and Saitoh, T. Dynamic behaviour analysis of internal combustion engine crankshafts under operating conditions. Proc. Inst. Mech. Eng., pp 205-209, 1991

[6] Hestermann, D. C. and Stone, B. J., Secondary inertia effects in the torsional vibration of reciprocating engines. Proc. Inst. Mech. Eng., 208(Cl), pp 11-15,1994

[7] Song, X. G., Song, T. X., Xue, D. X., and Li, B. Z., Progressive torsionalaxial continued vibrations in crankshaft systems: A phenomenon of coupled vibration. Trans. ASME, Rotating Mach. Vehicle Dyn., 35, pp 319-323, 1991

[8] Zhang, X. and Yu, S.D., Torsional vibration of crankshaft in an enginepropeller nonlinear dynamical system, Journal of Sound and Vibration, 319, pp 491-514, 2009 
[9] Pasricha, M.S. and Carnegie, W.D., Formulation of the equations of dynamic motion including the effects of variable inertia on the torsional vibrations in reciprocating engines-part 1 and 2, Journal of Sound and Vibration, 66 (2),pp 181-186, 1979

[10] Metallidis, P., and Natsiavas, S., Linear and nonlinear dynamics of reciprocating engines, International Journal of Non-Linear Mechanics, 38 (5) pp 723-738, 2003

[11] Gupta, S., Kelly, P., and Rahnejat, H., Elasto-multi-body dynamics of multi-cylinder internal combustion engine, Proceedings of ASME International Mechanical Engineering Congress and Exposition, Vol.2, pp.275-283, New York, United States, November 11-16, 2001

[12] Ma, Z.D., and N.C. Perkins, An efficient multibody dynamics model for internal combustion engine systems, International Conference Multibody System Dynamics, 10: pp 363-391, 2003

[13] Bakar, A.R.A, Jamaluddin, E. and Yin, L.C., An experimental investigation into noise and vibration of an automotive wiper, Regional Conference on Noise, Vibration and Comfort (NVC), pp 261-269, 2007

[14] Ewins, D.J., Modal Testing: Theory and Practice, Research Studies Press, Letchworth, 1984

[15] Sani, M.S.M, and Izham, M.H.N., Investigation modal parameter on chassis structure, $7^{\text {th }}$ UMT International Symposium on Sustainability Science and Management (UMTAS), 2008

[16] Kang, Y., Sheen, G.J., Tseng, M.H., Tu, S.H., and Chiang, H.W., Modal analyses and experiments for engine crankshafts, Journal of Sound and Vibration, 214(3), pp 413-430, 1998

[17] Bagci, C., and Rajavenkateswaran, S., Critical speed and modal analysis of rotating machinery using spatial finite line element method, Proceedings of the 4th International Modal Analysis Conference, pp 1708, 1987

[18] Smaili, A.A., and Khetawat, M.P., Dynamic modelling of automotive engine crankshafts, Mechanism and Machine Theory 29, pp 995-1006, 1994

[19] Stephenson, R.W., Rouch, K.E and Arora, R., Modelling of rotors with axisymmetric solid harmonic elements, Journal of Sound and Vibration, 131, pp 431-443,1989

[20] Stephenson, R.W., and Rouch, K.E, Modeling rotating shafts using axisymmetric solid finite elements with matrix reduction, ASME Journal of Vibration and Acoustics , 115, pp 484-489, 1993 